\title{
One Size Does Not Fit All-A Contingency Approach to Data Governance
}

\author{
KRISTIN WEBER, BORIS OTTO, and HUBERT ÖSTERLE \\ University of St. Gallen
}

Enterprizes need Data Quality Management (DQM) to respond to strategic and operational challenges demanding high-quality corporate data. Hitherto, companies have mostly assigned accountabilities for DQM to Information Technology (IT) departments. They have thereby neglected the organizational issues critical to successful DQM. With data governance, however, companies may implement corporate-wide accountabilities for DQM that encompass professionals from business and IT departments. This research aims at starting a scientific discussion on data governance by transferring concepts from IT governance and organizational theory to the previously largely ignored field of data governance. The article presents the first results of a community action research project on data governance comprising six international companies from various industries. It outlines a data governance model that consists of three components (data quality roles, decision areas, and responsibilities), which together form a responsibility assignment matrix. The data governance model documents data quality roles and their type of interaction with DQM activities. In addition, the article describes a data governance contingency model and demonstrates the influence of performance strategy, diversification breadth, organization structure, competitive strategy, degree of process harmonization, degree of market regulation, and decision-making style on data governance. Based on these findings, companies can structure their specific data governance model.

Categories and Subject Descriptors: H.1.1 [Models and Principles]: Systems and Information Theory-Information theory; value of information; K.6.1 [Management of Computing and Information Systems]: Project and People Management-Management techniques; staffing

General Terms: Management, Economics, Human Factors

Additional Key Words and Phrases: Data governance, IT governance, data quality management, data governance model, contingency theory

ACM Reference Format:

Weber, K., Otto, B., and Österle, H. 2009. One size does not fit all-a contingency approach to data governance. ACM J. Data Inform. Quality 1, 1, Article 4 (June 2009), 27 pages.

DOI $=10.1145 / 1515693.1515696$. http://doi.acm.org/10.1145/1515693.1515696.

Authors' address: K. Weber, B. Otto, and H. Österle, Institute of Information Management, University of St. Gallen, St. Gallen, Switzerland; email: Kristin.weber@unisg.ch.

Permission to make digital or hard copies of part or all of this work for personal or classroom use is granted without fee provided that copies are not made or distributed for profit or direct commercial advantage and that copies show this notice on the first page or initial screen of a display along with the full citation. Copyrights for components of this work owned by others than ACM must be honored. Abstracting with credit is permitted. To copy otherwise, to republish, to post on servers, to redistribute to lists, or to use any component of this work in other works requires prior specific permission and/or a fee. Permissions may be requested from the Publications Dept., ACM, Inc., 2 Penn Plaza, Suite 701, New York, NY 10121-0701 USA, fax +1 (212) 869-0481, or permissions@acm.org.

(c) 2009 ACM 1936-1955/2009/06-ART4 \$10.00 DOI: 10.1145/1515693.1515696.

http://doi.acm.org/10.1145/1515693.1515696.

ACM Journal of Data and Information Quality, Vol. 1, No. 1, Article 4, Pub. date: June 2009. 
4: $2 \quad$ K. Weber et al.

\section{INTRODUCTION}

Companies are forced to continuously adapt their business models. Global presence requires harmonized business processes across different continents, customers ask for individualized products, and service offerings must be industrialized [Kagermann and Österle 2006]. Data of high quality is a prerequisite to meet these changing business requirements and to achieve enterprize agility objectives [Newman and Logan 2006a]. In addition to such strategic factors, some operational domains directly rely on high-quality corporate data, such as business networking [Vermeer 2000; Madnick et al. 2004; Tellkamp et al. 2004], customer management [Zahay and Griffin 2003; Reid and Catterall 2005; Crié and Micheaux 2006], decision-making and business intelligence [Shankaranarayan et al. 2003; Price and Shanks 2005], and regulatory compliance [Friedman 2006].

Data Quality Management (DQM) focuses on the planning, provisioning, organization, usage, and disposal of high-quality data. In this sense, DQM addresses both technical and a number of organizational issues, such as maintaining sponsorship, managing expectation, avoiding scope creep, and handling political issues [Wang et al. 1998a; English 1999; Nohr 2001; Eppler 2006]. Therefore, DQM needs to integrate business and IT functions in order to address both organizational and technical perspectives [Bitterer and Newman 2007]. However, although there is collaboration between business and IT departments to a certain extent, the latter are often left in the lurch when it comes to improving data quality (DQ) and managing corporate data [Friedman 2006].

With data governance, companies are able to implement corporate-wide accountabilities for DQM, encompassing professionals from both business and IT departments. Data governance defines roles, and it assigns responsibilities for decision areas to these roles. It establishes organization-wide guidelines and standards for DQM, and it assures compliance with corporate strategy and laws governing data.

There has been only limited research on data governance. Apart from a few DQM approaches dealing with accountabilities [Redman 1996; English 1999], elaborate analysis of the interaction of roles and responsibilities and the design of decision-making structures is missing. Therefore, this investigation incorporates data governance sources from consultants, analysts, and practitioners [Swanton 2005; Dember 2006; Dyché and Levy 2006; Marco and Smith 2006; Newman and Logan 2006b; Russom 2006b; Bitterer and Newman 2007].

Both academic and practical sources presume data governance to be a universal approach; one that fits all organizations alike. Research on IT governance indicates that the distribution of accountabilities for IT management differs between companies based on contingencies, such as corporate governance mode or performance strategy. Moreover, several IT governance models exist, such as centralized and decentralized IT governance [Brown 1997; Sambamurthy and Zmud 1999; Brown and Grant 2005]. However, previous research has fallen short of providing comparable analyses concerning data governance and accountabilities for DQM. 
As data governance comprises parts of IT governance, this article suggests that contingencies affect data governance, and that a data governance configuration is specific to a given company. Basically, the article proposes a flexible data governance model composed of roles, decision areas, and responsibilities, and it outlines a contingency approach to data governance that demonstrates the fit between contingencies and the company-specific configuration of the model. In this respect, performance strategy, diversification breadth, organizational structure, competitive strategy, process harmonization, market regulation, and decision-making style have been identified as contingency factors. While this article focuses on the accountability aspect of data governance, it does not examine guidelines and compliance facets. The article outlines the first results of a data governance action research project the authors conducted with six international companies from various industries.

The contingency approach respects the fact that each company needs a specific data governance configuration that fits a set of context factors. A data governance model helps companies structure and document their data quality accountabilities. Contingencies and their influence on the model determine which configuration fits a company best. Finding the best model configuration would ensure that DQM contributes to the aforementioned business goals of a company. Neglecting to do so would mean that DQM runs the risk of being just an end in itself.

The remainder of the article is structured as follows: Section 2 provides a brief introduction to data quality management as well as an outline of the relation between IT governance and data governance. Section 3 outlines the design of the action research project the findings presented in the article are based on. Section 4 presents a flexible data governance model composed of roles, decision areas, and responsibilities, and it introduces two parameters that influence the design of the data governance model. Section 5 is devoted to the contingency approach to data governance. It outlines a contingency model that relates the data governance design (based on the two design parameters identified in Section 4) and a set of seven contingency factors to the prospects for successful DQM within an organization. Furthermore, Section 5 gives a short description of the evaluation of the contingencies in the action research project. Finally, Section 6 presents a brief summary of this article as well as a short discussion of both its managerial and research implications.

\section{BACKGROUND}

\subsection{Governance for Data Quality Management}

Governance in general "refers to the way the organization goes about ensuring that strategies are set, monitored, and achieved" [Rau 2004, p. 35]. Corporate governance sets the institutional and policy framework for corporations. Different accepted sources give recommendations for the definition of concrete policies and principles for corporate governance [e.g., OECD 2004]. Based on these principles, companies must translate the overall guidance into concrete 
guidelines for different organizational domains, such as the accounting department, the IT organization, or data quality management.

This article defines DQM as quality-oriented management of data as an asset, that is, the planning, provisioning, organization, usage, and disposal of data that supports both decision-making and operational business processes, as well as the design of the appropriate context, with the aim to improve data quality on a sustained basis. Data or information quality is defined on the basis of two consentient aspects: first, the dependence of perceived quality on the user's needs; second, the "fitness for use", which is the ability to satisfy the requirements of intended use in a specific situation [Wang and Strong 1996; Redman 2000]. One common denominator of these definitions is that data quality is considered a multifaceted construct, consisting of a set of data quality attributes (referred to as data quality dimensions) requiring consumer assessment [Wang and Strong 1996]. Examples of these dimensions are accuracy, completeness, consistency, relevancy, and timeliness.

As a matter of fact, a number of DQM approaches exist. Total Data Quality Management (TDQM), the best known approach, evolved from the TDQM program, which was initiated at the MIT in 1991 with the long-term vision to build a new paradigm for data quality management and to develop a rigorous theoretical foundation for data quality [Wang 1998; Wang et al. 1998b; Huang et al. 1999]. Other approaches are Total Quality data Management (TQdM) [English 1999], the framework for Information Quality Management (IQM) [Eppler 2006], and data quality for the information age [Redman 1996]. Their contributions to data governance will be discussed in Section 2.3.

\subsection{The Use of Contingency Theory in IT Governance}

The goal of IT governance is to ensure that IT is a valued and embedded element for business and is enabling, not constraining, a company's overall strategy. IT governance (as a subset of corporate governance) "assists in the achievement of corporate success by both efficiently and effectively deploying secure and reliable information through the application of technology" [Korac-Kakabadse and Kakabadse 2001, p. 9]. This generic objective is operationalized through reference frameworks which help IT managers analyze IT issues from a business perspective and transform IT departments into service providers. Among the best known and most frequently used frameworks are the IT Infrastructure Library (ITIL) and the Control Objectives for Information and Related Technology (CobiT) [Curtis et al. 2005].

From a scientific perspective, IT governance researchers point to the importance of aligning IT governance arrangements with the overall organizational context. Scholars investigated the relationship between organizations' IT governance design and organizational context factors [Brown 1997; Sambamurthy and Zmud 1999; Korac-Kakabadse and Kakabadse 2001; Brown and Grant 2005; Weill and Ross 2005]. The underlying assumption is that there is no universal IT governance design for all organizations and that the context factors impact the contribution of IT governance in enhancing corporate performance. 
Contingency theory of organizational design has outlined similar dependencies: The relationship between some characteristic of an organization and its organizational effectiveness is determined by contingencies. Traditionally, contingency theory addressed environmental fit or fit of organizational structure with environmental conditions [Burns and Stalker 1961; Lawrence and Lorsch 1967]. Scholars later enhanced contingency theory by taking into account internal conditions, such as structural formalization and specialization or technology, as being contingencies [Woodward 1980; Miller 1992; Donaldson 2001; Keats and O'Neill 2001].

Following this contingency approach, IT governance research came up with IT governance patterns or models, each model fitting a different set of contingencies. Early studies examined the singular effects of organizational context variables taken from classical contingency theory (such as organization size, competitive strategy, locus of decision-making authority/control) on single IT functions [Olson and Chervany 1980; Ein-Dor and Segev 1982; Ahituv et al. 1989; Tavakolian 1989]. They proposed two IT governance models: In centralized models, corporate IT performs all IT functions, whereas in decentralized models business units' IT performs these tasks. A third pattern, the federal model, distinguishes between two types of IT functions: The management of the use of IT is decentralized to business units, and the management of IT is centralized [Boynton and Zmud 1987; Hodgkinson 1996].

Acknowledging the fact that organizations are influenced by more than one contingency factor at the same time, Sambamurthy and Zmud [1999] investigated the influence of multiple contingencies on the location of IT decision rights (decentralized, centralized, and federal). Further, they added a third type of IT function and distinguished between IT infrastructure management, IT use management, and project management. The reasoning behind IT governance shifted from performance of IT functions to authority for IT decision-making within these functions. Brown [1997] shifted the focus from organizational level to business-unit level. In the hybrid model she proposed, the IT use function is decentralized to some but not all business units within the same organization. She argued that to understand these different arrangements, context variables need to be addressed at the business-unit level.

The IT governance archetypes proposed by Weill [2004] further contribute to a more elaborated view on IT governance models. Instead of two organizational units (corporate IT versus line IT), he considers senior business executives, IT professionals from corporate teams and business units, and business-unit leaders or business process owners having decision authority for IT management functions. In addition, he distinguishes five major decision areas, namely IT principles, IT architecture, IT infrastructure strategies, business application needs, and IT investment and prioritization. Finally, he extends IT governance models by a third element: the distinction between decision rights and input rights. However, he limited the number of possible combinations of these three dimensions to six mutually exclusive archetypes. Although the archetypes define IT governance on an organization-wide level, Weill suggested that IT governance in large enterprizes should also be 
4: $6 \quad$ K. Weber et al.

designed and assessed on a business-unit level, or by region or groups of business units.

In conclusion, IT governance research has analyzed two domains: the organizational structuring of IT activities together with the placement of decisionmaking authority, and the effect of multiple contingencies on the contribution of IT governance to corporate performance. It proposes three dimensions that constitute an IT governance model: roles, major decision areas, and assignment of accountabilities. IT governance models can be designed on several organizational levels.

Despite the large body of IT governance research analyzing contingencies, context is scarcely addressed in the reference frameworks ITIL and CobiT. "Best-practice" processes for delivery and support of IT services defined in ITIL follow the "one size fits all" maxim. The generic CobiT framework may be adapted to a company's specific context by mapping its strategic goals to IT goals. The framework thereby indicates which of CobiT's processes the company should apply. However, contingencies are not addressed within those processes, that is, the framework does not specify how the processes should be applied in different contexts.

\subsection{Data Governance}

Data governance specifies the framework for decision rights and accountabilities to encourage desirable behavior in the use of data. ${ }^{1}$ To promote desirable behavior, data governance develops and implements corporate-wide data policies, guidelines, and standards that are consistent with the organization's mission, strategy, values, norms, and culture (refer to Weill [2004]). Data is often distinguished from information by referring to data as "raw" or simple facts and to information as data put in a context or data that has been processed [Huang et al. 1999; Price and Shanks 2005]. In line with most data or information quality publications, the terms data and information are used interchangeably throughout the article.

Compared with the extensive body of IT governance research, academic research on data governance is still in its infancy. DQM approaches address tasks of improving and sustaining high-quality data. For example, TDQM [Wang 1998; Wang et al. 1998a; Huang et al. 1999] proposes detailed tasks of defining, measuring, analyzing, and improving information quality organized in a cycle. These approaches deal with DQM accountabilities by describing data quality roles and their responsibilities. English [1999], for example, portrays 19 roles and their responsibilities in his TQdM approach. He distinguishes business responsibilities from IT responsibilities and suggests three teams with overarching accountability for specific decisions. Table I depicts the contribution of these two DQM approaches to data governance, as well as the contribution of the framework for IQM [Eppler 2006] and the data quality program by Redman [1996]. These four approaches have been chosen because they represent comprehensive DQM examinations with a substantial portion ${ }^{1}$ In the absence of academic definitions of data governance, this definition was adapted from the
IT governance definition of Weill [2004]. 
Table I. Data Quality Management Approaches and their Contribution to Data Governance

\begin{tabular}{|l|l|l|l|}
\hline DQM approach & \multicolumn{1}{|c|}{ Roles } & Decision areas / Tasks & \multicolumn{1}{|c|}{ Accountabilities } \\
\hline $\begin{array}{l}\text { TDQM [Wang 1998; } \\
\text { Wuang et al. 1998a; }\end{array}$ & $\begin{array}{l}\text { Information } \\
\text { Product Manager } \\
\text { (IPM), collector, } \\
\text { custodian, } \\
\text { consumer }\end{array}$ & $\begin{array}{l}\text { TDQM cycle } \\
\text { (define, measure, } \\
\text { analyze, improve) }\end{array}$ & $\begin{array}{l}\text { IPM manages } \\
\text { information process } \\
\text { and resulting } \\
\text { product }\end{array}$ \\
\hline $\begin{array}{l}\text { TQdM } \\
\text { [English 1999] }\end{array}$ & $\begin{array}{l}\text { (from business } \\
\text { and IT, incl. } \\
\text { three teams) }\end{array}$ & $\begin{array}{l}\text { TQdM methodology } \\
\text { (five processes } \\
\text { for measuring and } \\
\text { improving DQ) }\end{array}$ & $\begin{array}{l}\text { Each role has defined } \\
\text { accountabilities; } \\
\text { teams have overall } \\
\text { and problem-solving } \\
\text { authority }\end{array}$ \\
\hline $\begin{array}{l}\text { Framework } \\
\text { for IQM }\end{array}$ & $\begin{array}{l}\text { Line managers, } \\
\text { domain experts, }\end{array}$ & $\begin{array}{l}\text { Matrix with four } \\
\text { views (target community, } \\
\text { information product, } \\
\text { information processes, } \\
\text { infrastructure) and } \\
\text { four phases in the } \\
\text { information life cycle }\end{array}$ & $\begin{array}{l}\text { responsible for } \\
\text { one view; top } \\
\text { management has } \\
\text { additional } \\
\text { strategic and } \\
\text { tactical tasks }\end{array}$ \\
\hline $\begin{array}{l}\text { IT support } \\
\text { staff, and top } \\
\text { management } \\
\text { [nformation age }\end{array}$ & $\begin{array}{l}\text { Leaders, } \\
\text { process owners, } \\
\text { information } \\
\text { professionals }\end{array}$ & $\begin{array}{l}\text { DQ program (error } \\
\text { detection, process } \\
\text { control and } \\
\text { improvement, process } \\
\text { design, DQ policy) }\end{array}$ & $\begin{array}{l}\text { Each role } \\
\text { has defined } \\
\text { accountabilities }\end{array}$ \\
& & & \\
\hline
\end{tabular}

of business-related responsibilities. They focus on long-term data quality improvement and error prevention rather than error correction.

In addition to these DQM approaches, this investigation analyzed data governance [Dember 2006; Dyché and Levy 2006; Marco and Smith 2006; Russom 2006b; Bitterer and Newman 2007], master data governance [Swanton 2005], and information governance [Newman and Logan 2006b] sources from consultants, analysts, and practitioners. All these approaches propose between three and five key roles for data quality programs and outline their responsibilities. They use the term "data stewardship" to refer to accountabilities, committal, and collaborative business practices for managing data as an asset [Bitterer and Newman 2007]. In their book on Customer Data Integration (CDI) Dyché and Levy [2006] devote a chapter to data governance and stewardship. For their twelve CDI roles, they suggest detailed skill profiles to facilitate the assignment of employees to roles.

In conclusion, all available data governance sources from scholars and practitioners focus on organizational structuring and the placement of decisionmaking authority for DQM. However, an elaborate analysis of the interaction of roles and responsibilities and the design of decision-making structures is missing. Compared with IT governance research, data governance sources have, up to this point, only addressed one of the two domains. All sources postulate a universal data governance approach, namely one that should fit all organizations alike. At the same time, they fall short of analyzing the interrelation of the distribution of accountabilities for DQM and contingency factors. Moreover, they do not come up with more than one data governance design. This might be the reason why companies find it difficult to set up 
4: $8 \quad$ K. Weber et al.

and maintain organizational structures designed to assure and sustain highquality data throughout the entire organization. The findings of a survey among data management professionals indicate that data governance is rarely adopted [Russom 2006b]. Only 8\% of respondents had deployed a data governance initiative, while $17 \%$ were in the design or implementation phase.

\section{ACTION RESEARCH DESIGN}

The context of this research is set by the research project Corporate Data Quality at the University of St. Gallen launched in November 2006. In this project, subject matter experts from six industry partner companies and a group of five researchers are conjointly doing applied research to improve corporate data quality (for a description of the companies, see the Appendix). During the twoyear period of the research project, two-day workshops take place every two or three months in which practitioners (from the partner companies and invited guests) and researchers (from the University of St. Gallen as well as invited experts) discuss one or two key topics. In addition to the workshops, each partner company participates in individual projects aimed at solving company-specific corporate data quality problems.

This kind of research project can be designated as community action research. Community action research is an approach of collaborative knowledge creation carried out by a community of practitioners, consultants, and researchers [Senge and Scharmer 2001]. Action research in general puts researchers in a helping role within the organizations studied and produces highly relevant research findings [Baskerville and Wood-Harper 1998]. It aims at solving current practical problems, while at the same time expanding scientific knowledge [Hult and Lennung 1980]. Community action research specifically focuses on fostering collaboration among diverse organizations, creating settings for collective reflection, and leveraging transformation in participating organizations through cross-institutional links [Senge and Scharmer 2001].

The individual projects in the partner companies follow canonical action research. The primary goal of canonical action research is organizational development, that is, improving regular patterns of social interaction through higher morale, structural efficiency, structural effectiveness, or improved information flows [Baskerville and Wood-Harper 1998]. Data governance refers to all these aspects of organizational change. Through the definition of clear accountabilities, it results in higher efficiency, higher effectiveness, and improved information flows in the context of DQM. In canonical action research, an iterative research process consisting of diagnosis, action planning, action taking, evaluation, and specifying learning is repeated in cycles until the practical problem is solved [Baskerville and Wood-Harper 1998]. It also implies a collaborative involvement of researchers and practitioners. Both parties bring their equally valuable, distinctive sets of knowledge into the research, which consists of general theories on the part of researchers, and situational, practical knowledge on the part of practitioners [Baskerville and Myers 2004].

ACM Journal of Data and Information Quality, Vol. 1, No. 1, Article 4, Pub. date: June 2009. 
The topic of this article, a contingency approach to data governance, was the main subject of one of the workshops, that took place in September 2007. The objective of the workshops was to evaluate the suitability of a data governance contingency approach and to discuss a proposed set of contingencies from IT governance research. Nearly 15 practitioners participated in the workshop. Most participants were from the 6 partner companies, others were external data quality experts and consultants, who were invited to join the workshop. After the researchers had presented the state-of-the-art and their ideas, the practitioners discussed the contingency approach in two groups moderated by the researchers. The central questions in both groups were: Is the list of contingencies complete? And: How can one assess their appropriateness? One participant of each group presented the group's work results to the other participants in order to discuss them and to reach common agreement (refer to Section 5).

The researchers gained additional insights into the suitability of contingency approach to data governance from three individual action research projects focusing on data governance. Each of the three companies aims at establishing an organizational structure that facilitates the production and maintenance of high-quality master data (companies A and F) or infrastructure data (company C). From the researchers' point of view, one goal is to develop organizational infrastructures that will enable the participating organizations to plan, organize, learn, and help themselves [Susman and Evered 1978; Jarvinen 2000]. The second goal is to contribute to the scientific knowledge about data governance. In the course of the iterative action research cycle process, all three companies currently are in the action-taking phase of the first iteration cycle. Through workshops and discussions with many different stakeholders in the companies, the researchers increased their understanding about the practical implications of the contingency approach (refer to Section 5).

\section{DATA GOVERNANCE MODEL}

\subsection{Components of the Data Governance Model}

The data governance model consists of DQM decision areas and main activities, roles, and responsibilities, namely, the assignment of roles to decision areas and main activities. The three components can be arranged in a matrix (refer to Figure 1). The rows of the matrix identify the key decision areas and main activities, while the columns indicate the roles in DQM. The cells of the matrix contain the responsibilities/types of interaction, that is, they specify degrees of authority between roles and decision areas. A company designs its individual data governance configuration by defining data quality roles, decision areas, and responsibilities, and by subsequently arranging the components into the model. This configuration is unique for each company. ${ }^{2}$

From the analysis of literature relating to DQM and data governance (as outlined in Section 2.3), the data governance model uses a set of four roles and

${ }^{2}$ This section is based on previous research by one of the authors. Wende [2007] provides a more extensive overview of the matters presented. 


\begin{tabular}{|c|c|c|c|c|}
\hline & $\begin{array}{c}\text { DQM } \\
\text { Role 1 }\end{array}$ & $\begin{array}{c}\text { DQM } \\
\text { Role 2 }\end{array}$ & $\begin{array}{c}\text { DQM } \\
\text { Role 3 }\end{array}$ & $\begin{array}{c}\text { DQM } \\
\text { Role } \mathbf{n}\end{array}$ \\
\hline DQM Task 1 & {$[R|A| C \mid I]$} & {$[R|A| C \mid I]$} & {$[R|A| C \mid I]$} & \\
{$[R|A| C \mid I]$}
\end{tabular}

R-Responsible; A - Accountable; C - Consulted; I-Informed

Fig. 1. Schematic representation of a data governance model.

one committee, the data quality board. Table II provides a short description of each role, the level and part of the organization to which this role typically belongs, and alternative names of the role found in literature. Within the last column, names in brackets only partly match either the description or organizational assignment.

DQM not only covers technical or system-related aspects but also businessrelated and organizational issues. This interdependency between a company's IT and its business goals has been emphasized by Davenport [1993], addressing the overall linkage between strategy and IT via processes, and also by Hammer and Champy [1993], who explicitly deal with the supportive role of IT for business processes. Interlinkage between business strategy, processes, and IT has further been substantiated and operationalized in the field of business engineering [Österle and Winter 2003]. With reference to business engineering, the data governance model addresses DQM on three horizontal layers: strategy, organization, and information systems. The following decision areas and key tasks represent a consensus from existing approaches to DQM [Redman 1996; Wang et al. 1998a; English 1999; Nohr 2001; Eppler 2006].

Strategy. The strategy perspective of DQM includes a corporate data quality strategy which links corporate data management with major business drivers and outlines strategic goals. Further components of the strategic perspective are the business case for corporate data management and the installation of a maturity assessment. Main tasks include:

- develop a corporate data quality strategy, including strategic objectives;

- define a portfolio of strategic corporate data quality initiatives;

-formulate the business case for corporate DQM; and

- carry out a status quo assessment and establish a review process.

Organization. The second layer consists of organizational and processrelated aspects. It includes the establishment of appropriate measurement and control systems in order to monitor and improve the performance of DQM. It also covers the definition and assignment of roles, as well as the definition of corporate data management processes. Typically, the latter determine how corporate data objects, such as materials master data, vendor master data, 
Table II. Set of Data Quality Roles

\begin{tabular}{|c|c|c|c|}
\hline Role & Description & $\begin{array}{c}\text { Organizational } \\
\text { Assignment }\end{array}$ & Sources \\
\hline $\begin{array}{l}\text { Executive } \\
\text { Sponsor }\end{array}$ & $\begin{array}{l}\text { Provides sponsorship, } \\
\text { strategic direction, } \\
\text { funding, advocacy, } \\
\text { and oversight for } \\
\text { DQM }\end{array}$ & $\begin{array}{l}\text { Executive or } \\
\text { senior manager, } \\
\text { e.g., CEO, CFO, } \\
\text { CIO }\end{array}$ & $\begin{array}{l}\text { Strategic information } \\
\text { steward [English 1999], } \\
\text { executive level } \\
\text { [Newman and Logan 2006b], } \\
\text { executive sponsor } \\
\text { [Marco and Smith 2006], } \\
\text { (executive council) } \\
\text { [Dember 2006] }\end{array}$ \\
\hline $\begin{array}{l}\text { Data } \\
\text { Quality } \\
\text { Board }\end{array}$ & $\begin{array}{l}\text { Defines the data } \\
\text { governance framework } \\
\text { for the whole } \\
\text { enterprize and } \\
\text { controls its } \\
\text { implementation }\end{array}$ & $\begin{array}{l}\text { Committee, } \\
\text { chaired by chief } \\
\text { steward, members } \\
\text { are business unit } \\
\text { and IT leaders as } \\
\text { well as data } \\
\text { stewards }\end{array}$ & $\begin{array}{l}\text { Business information } \\
\text { stewardship team } \\
\text { [English 1999], data } \\
\text { governance council } \\
\text { [Dyché and Levy 2006; } \\
\text { Marco and Smith 2006], } \\
\text { data overnance committee } \\
\text { [Russom 2006b], GRCS } \\
\text { board [Dember 2006], trustee } \\
\text { council [Dyché and Levy 2006], } \\
\text { (legislative level) } \\
\text { [Newman and Logan 2006b] }\end{array}$ \\
\hline $\begin{array}{l}\text { Chief } \\
\text { Steward }\end{array}$ & $\begin{array}{l}\text { Puts the board's } \\
\text { decisions into } \\
\text { practice, enforces } \\
\text { the adoption of } \\
\text { standards, helps } \\
\text { establish DQ } \\
\text { metrics and targets }\end{array}$ & $\begin{array}{l}\text { Senior manager } \\
\text { with data } \\
\text { management } \\
\text { background }\end{array}$ & $\begin{array}{l}\text { Master data coordinator } \\
\text { [Swanton 2005], director } \\
\text { of data management } \\
\text { [Dyché and Levy 2006], chief } \\
\text { steward [Marco and Smith } \\
\text { 2006], corporate steward } \\
\text { [Russom 2006b], lead } \\
\text { stewards [Dember 2006], } \\
\text { (data czar) [Dyché } \\
\text { and Levy 2006] }\end{array}$ \\
\hline $\begin{array}{l}\text { Business } \\
\text { Data } \\
\text { Steward }\end{array}$ & $\begin{array}{l}\text { Details corporate-wide } \\
\text { DQ standards and } \\
\text { policies for his/her } \\
\text { area of responsibility } \\
\text { from a business } \\
\text { perspective }\end{array}$ & $\begin{array}{l}\text { Professional from } \\
\text { business unit } \\
\text { or functional } \\
\text { department }\end{array}$ & $\begin{array}{l}\text { Information professionals } \\
\text { [Redman 1996], business } \\
\text { information steward } \\
\text { [English 1999], business } \\
\text { data steward [Dyché and } \\
\text { Levy 2006], subject area } \\
\text { steward [Newman and } \\
\text { Logan 2006b], master data } \\
\text { lead [Swanton 2005], } \\
\text { domain steward } \\
\text { [Russom 2006b], } \\
\text { business steward } \\
\text { [Marco and Smith 2006], } \\
\text { subject matter expert } \\
\text { [Dyché and Levy 2006] }\end{array}$ \\
\hline $\begin{array}{l}\text { Technical } \\
\text { Data } \\
\text { Steward }\end{array}$ & $\begin{array}{l}\text { Provides standardized } \\
\text { data element } \\
\text { definitions and } \\
\text { formats, profiles and } \\
\text { explains source } \\
\text { system details } \\
\text { and data flows } \\
\text { between systems }\end{array}$ & $\begin{array}{l}\text { Professional from } \\
\text { IT department }\end{array}$ & $\begin{array}{l}\text { Database steward and } \\
\text { information architecture } \\
\text { steward [English 1999], } \\
\text { technical steward } \\
\text { [Marco and Smith 2006], } \\
\text { source system data } \\
\text { steward [Dyché and } \\
\text { Levy 2006] }\end{array}$ \\
\hline
\end{tabular}




\section{4: $12 \quad$ K. Weber et al.}

and customer master data, are created, maintained, used, and deleted. More particularly, main activities include:

- determine metrics to measure corporate data quality;

- define roles and responsibilities as well as staff roles;

-identify and assign ownership of corporate data objects;

— define data management processes; and

-assign ownership for data management processes.

Information Systems. The information systems perspective combines the development of a corporate data model on a logical level, the design of the data architecture, which deals (among other things) with the validity of corporate data objects in the organizational context, and the definition of system support. Main activities on the information systems layer are:

-identify corporate data objects;

- develop unambiguous definitions for corporate data objects;

- establish a business data dictionary;

- assign quality dimensions to corporate data objects;

-define "data storage";

- establish a corporate data infrastructure;

- define principles for distribution of corporate data between systems; and

- define the utilization of cleansing methodologies and tools.

The assignment of responsibilities to roles in the data governance model follows the idea of a Responsibility Assignment Matrix (RAM) (e.g., Crowe [2005]). The most popular type of RAM is the RACI chart. For example, the IT governance reference framework CobiT uses the RACI chart to define responsibilities [IT Governance Institute 2005]. RACI is an acronym for the four types of interaction: Responsible, Accountable, Consulted, and Informed. Mapped to the domain of DQM, these types are specified as follows.

-Responsible (" $R$ ”). This role is responsible for executing a particular DQM activity.

-Accountable (“A”). This role is ultimately accountable for authorizing a decision regarding a particular DQM activity.

—Consulted ("C"). This role may or must be consulted to provide input and support for a DQM activity or decision before it is completed.

-Informed ("I"). This role may or must be informed of the completion or output of a decision or activity.

The abbreviations "R", "A", "C", and "I" fill the cells of the matrix to depict the kind of responsibility a role has for a specific DQM activity or decision. Contrary to project and change management handbooks (e.g., Cohen and Roussel [2004], Crowe [2005]), the data governance model allows more than one "A" in a row, that is, more than one role may be accountable for authorizing a decision. This approach respects a cooperative culture and conjointly made 
decisions. However, only one " $R$ " is allowed per row, that is, only one role is ultimately responsible for executing an activity. This rule guarantees the commitment of one single role for taking care of a certain task. This approach takes into account that one role coordinates multiple stakeholders' interests on aspects such as information lifecycle requirements or quality goals for information objects [Wang et al. 1998a]. However, the decision as to whether, for example, an external numbering system shall be used for unambiguous identification of vendor master data is made by multiple business departments, such as purchasing and accounts payable. Therefore, exactly one role is responsible for the execution of an activity (one "R") but allows for collaborative decisionmaking (multiple "A"). Alternatively, one "A" may be assigned to a committee and thereby to all members of the very committee.

This data governance model with its roles, decisions areas, and responsibility assignments represents a common denominator. When applying the model in practice, however, companies will configure it to their individual needs by elaborating the distribution of interaction types, and by involving additional roles and decision areas in response to specific requirements. The two design parameters described in the next section will facilitate the distribution of responsibilities within the matrix.

\subsection{Data Governance Design Parameters}

The design of the data governance model is company-specific, especially the distribution of responsibilities within the matrix. The definition of two design parameters, however, facilitates the comparison of different data governance models in order to identify differences and similarities. In addition, the parameters provide companies with an indication of the distribution of the responsibilities. In the context of DQM, these parameters are "organizational structuring of DQM activities" and "coordination of decision-making for DQM." They range between two opposed value pairs: centralized/decentralized and hierarchical/cooperative. The design parameters affect the configuration of the data governance model, that is, their values influence the assignment of responsibilities within the matrix. The following sections justify the two design parameters by referring to IT governance publications. They demonstrate how the design parameters affect the configuration of the data governance model. Two tables summarize these effects, that is, they specify the assignment of responsibilities to the data quality roles using the RACI notation.

4.2.1 Organizational Structuring of DQM Activities. IT governance research has analyzed the organizational placement of decision-making authority and the organizational structuring of IT activities in large, multi-divisional organizations [Brown 1997; Brown and Magill 1998; Peterson 2004; Brown and Grant 2005]. Two patterns have been distinguished: a centralized and a decentralized IT governance design. The centralized design places all decisionmaking authority in a central IT department. In case of decentralized design, decision-making authority is distributed over individual business units, business divisions, or lines of business. 
4: $14 \quad$ K. Weber et al.

Table III. Specification of Data Governance Model for Parameter "Organizational Structuring”

\begin{tabular}{|l|l|l|}
\hline Role & $\begin{array}{c}\text { Centralized Data } \\
\text { Governance Design }\end{array}$ & $\begin{array}{c}\text { Decentralized Data } \\
\text { Governance Design }\end{array}$ \\
\hline Executive sponsor & $\begin{array}{c}\text { "A" in some decisions } \\
\text { of major relevance }\end{array}$ & $\begin{array}{c}\text { "C" (recommending, } \\
\text { ot commanding) }\end{array}$ \\
\hline Data quality board & Many "A" & Many "C", "I", no "A" alone \\
\hline Chief steward & Many "A" & "C", (obsolete) \\
\hline Business \& technical data steward & "R", few "A" & Many "A", "R" \\
\hline
\end{tabular}

Centralized IT governance leads to greater control over IT standards and enables the realization of economies of scale. Decentralized IT governance allows greater responsiveness and flexibility with regard to business needs and customized solutions for each business unit [Peterson 2004; Brown and Grant 2005]. Consequently, companies need to balance the trade-off between standardization and centralized direction on the one hand, and flexibility and decentralized input to IT decisions on the other. Scholars have responded to this dilemma and introduced more complex IT governance models, such as federal IT governance (see Section 2.2).

"Organizational structuring of DQM activities" is the first design parameter for the data governance model. The parameter spans a continuum between the two extremes of centralized and decentralized data governance (refer to Table III). In a strict centralized data governance approach, all decisionmaking authority resides in a central DQM role, such as the chief steward or the data quality board. The chief steward usually is employed at the corporate center. The executive sponsor regularly participates in data quality board meetings and authorizes essential decisions, such as the data quality strategy. Decisions made with respect to processes, metrics, standards, architecture, guidelines, etc., are valid throughout the whole enterprize. A strict decentralized data governance approach places decision-making authority in the hands of business and technical data stewards. A chief data steward might even be obsolete in this design. Decisions made by the data quality board are recommendations rather than rules or standards. Alternatively, the company may establish two levels of data quality boards: one at the corporate level having an advisory function, and one in each business unit with decision-making authority (refer to Peterson [2004] and Rau [2004]. Business and technical data stewards decide autonomously for their area of responsibility. In addition to the top management executive sponsor, every business unit might have its own sponsor from the business-unit management.

4.2.2 Coordination of Decision-Making for DQM Activities. Although scholars have suggested increasingly complex IT governance models, they essentially focus on structural considerations regarding IT governance. These considerations have been questioned recently, and IT governance research augmented the structural perspective with a process perspective [Patel 2002; Peterson 2004; Dahlberg and Kivijärvi 2006]. This perspective acknowledges how complex organizations operate, which integration devices they use, how information flows between actors, and how the decision-making processes are 


One Size Does Not Fit All-A Contingency Approach to Data Governance • $4: 15$
Table IV. Specification of Data $\begin{aligned} & \text { Governance Model for Parameter "Coordination of } \\
& \text { Decision-Making" }\end{aligned}$
\begin{tabular}{|l|l|l|}
\hline Role & $\begin{array}{c}\text { Hierarchical Data } \\
\text { Governance Design }\end{array}$ & $\begin{array}{c}\text { Cooperative Data } \\
\text { Governance Design }\end{array}$ \\
\hline Executive sponsor & $\begin{array}{c}\text { "A" in some decisions } \\
\text { of major relevance }\end{array}$ & "A" (conjointly) \\
\hline Data quality board & "A" (separately) & Many "C" and "A" (conjointly) \\
\hline Chief steward & "A" (separately) & "C", "I", few "A" \\
\hline Business \& technical data steward & "R", "I", few "C" & Many "A" (conjointly) and "C" \\
\hline
\end{tabular}

configured [Peterson 2004]. Coordination of decision-making authority relies on either hierarchical (or vertical) lines or collaborative (or horizontal) capabilities [Peterson 2004]. The hierarchical IT governance design is characterized by a pyramid-like structure with power at the top exercised by a person or group, such as the CIO or IT governance board. Coordination is achieved through superiors delegating to, communicating with, and controlling and monitoring their direct subordinates, who in turn delegate to, control, etc., their direct subordinates. Information flows from top to bottom and vice versa. In cooperative IT governance design, direct control is replaced with collaborative and democratic behavior to clarify differences and solve problems [Dallas 2004; Peterson 2004]. It integrates formal and informal coordination mechanisms across business units (and IT) [Brown 1999].

"Coordination of decision-making for DQM activities" is the second design parameter for the data governance model. The two extremes of this parameter's continuum are hierarchical and cooperative data governance (refer to Table IV). The hierarchical data governance model is characterized by a topdown decision-making approach. Either the chief steward or the data quality board has decision-making authority for a single DQM activity. The data quality board has few members, usually from first-level and second-level management. Tasks are delegated to business and technical data stewards. However, they are not directly involved in decision-making. The cooperative data governance model applies formal and informal coordination mechanisms to reach decisions. Working groups, task forces, and committees with members from multiple disciplines complement the data quality board (refer to Dallas [2004]). No single role makes a decision on its own. New integrator roles, such as process owners or data architects that report to business units, establish a high degree of cross-unit collaboration (refer to Brown [1999]). These formal coordination mechanisms can be complemented by informal mechanisms, such as interdepartmental events, job rotation, or cross-unit input to performance reviews [Brown 1999].

\section{TOWARDS A CONTINGENCY APPROACH TO DATA GOVERNANCE}

\subsection{Data Governance Contingency Model}

Previous data governance research has provided organizational structures that should fit all companies alike. It has thereby neglected the fact that each 


\section{4: $16 \quad$ K. Weber et al.}

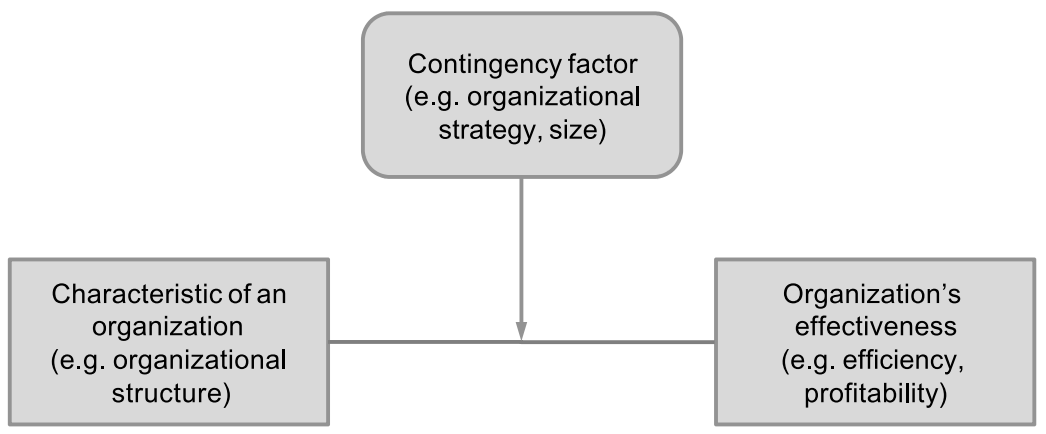

Fig. 2. Moderation model (contingency as covariation effect) adapted from Umanath [2003, p. 554].

company requires a specific data governance configuration that fits a set of specific contingencies. As opposed to this, the data governance model described in Section 4 allows for company-specific configuration of data governance. This section outlines a contingency approach to data governance, explaining which contingencies affect the fit between a company-specific data governance model and successful DQM and how these contingencies do so. A detailed explanation of the variables of the data governance contingency model follows in subsequent sections.

The contingency model of data governance is based on the contingency theory of organizational design. Contingency theory says that the relationship between some characteristic of an organization and the organization's effectiveness is determined by contingencies [Donaldson 2001]. An appropriate organizational structure (e.g., hierarchical or functional) which actually "fits" the contingency factors, such as the size of the organization or the organizational strategy, is considered to have a positive effect on the organization's efficiency, profitability, or innovation rate. The data governance contingency model is a moderation model with contingencies as covariation effects [Umanath 2003, p. 554]: "Fit as moderation espouses the idea of explaining/predicting variation in a criterion variable (e.g. performance) in terms of covariation between predictor (e.g. context) and moderator (e.g. structure) variables." The moderation model is depicted in Figure 2.

In the data governance contingency model, the predictor or independent variable (i.e., the characteristic of an organization) is the company-specific design of the data governance model. Simplified, the model is represented by the design of the two design parameters "organizational placement of DQM activities" and "coordination of decision-making for DQM" (refer to Section 4.2).

The moderator variables (i.e., the contingency factors) affect the relation between the company-specific data governance model and successful DQM. The seven contingency factors are: performance strategy, organization structure, competitive strategy, diversification breadth, process harmonization, market regulation, and decision-making style. Whereas the first six factors influence the relation between the design parameter "organizational placement of DQM activities" and successful DQM, the last factor (decision-making style) 


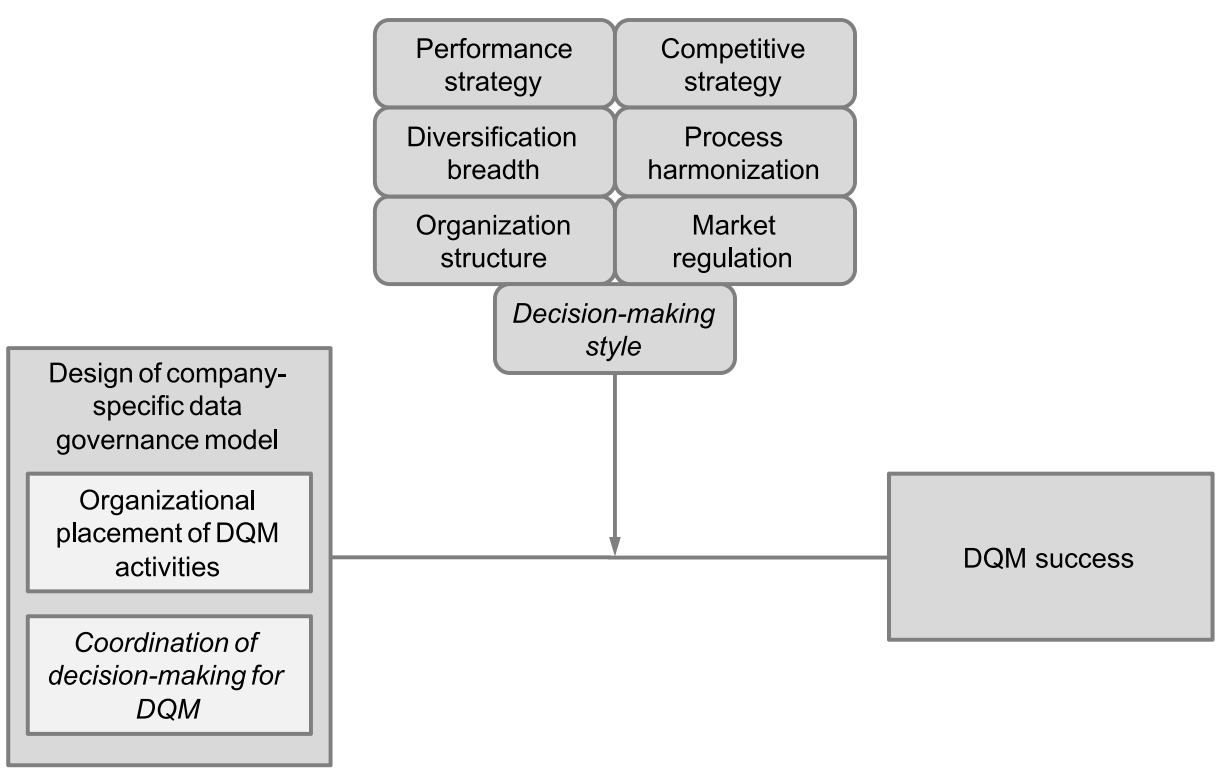

Fig. 3. Data governance contingency model.

influences the relation between the parameter "coordination of decisionmaking activities" and successful DQM.

The contingency factors determine the fit between the design of the data governance model and the success of DQM within the organization (i.e., the organization's effectiveness). Only if the data governance design is appropriate for the company-specific contingencies values will DQM be successful. For example, a multi-business organization with very diverse products operating in many markets (i.e., with a high diversification breadth) probably won't be successful with a data governance model that emphasizes company-wide standards and strict control from corporate headquarters. Therefore, the success of DQM is the dependent variable in the contingency model. The elements of the data governance contingency model are depicted in Figure 3.

The following two sections explain in more detail the contingency factors that affect the fit between the two design parameters and successful DQM. Based on research on IT governance, the researchers selected an initial set of seven contingency factors representing the state-of-the-art. These factors were evaluated during the workshop by the industry experts (refer to Section 3). The result, a set of seven contingency factors for data governance, is depicted in Figure 3. Discussing the identified factors with a different set of practitioners might result in a third set of contingency factors. However, Section 5.4 will illustrate that the identified factors have an impact on data governance design. The contingency model presented is a first advance towards a contingency theory of data governance. More evaluation is necessary in order to attest the model's general applicability. Table V compares the two sets of contingency factors. 
4: $18 \quad$ K. Weber et al.

Table V. Comparison of Contingency Factors Sets

\begin{tabular}{|l|l|}
\hline Contingency Factors (IT Governance) & Contingency Factors (Data Governance) \\
\hline Performance strategy & Performance strategy \\
Firm size (not relevant for DG) & Diversification breadth \\
Diversification breadth & Organization structure \\
Organization structure & Competitive strategy \\
Competitive strategy & Degree of process harmonization (new) \\
Line IT knowledge (not relevant for DG) & Degree of market regulation (new) \\
Decision-making style / culture & Decision-making style / culture \\
\hline \multicolumn{2}{|l}{ Key: italic = relates to parameter "coordination of decision-making.” }
\end{tabular}

\subsection{Organizational Placement of DQM Activities}

The following IT governance contingency factors influence the relation between the organizational placement of decision-making authority and the organization's effectiveness (here, IT success): performance strategy, firm size, diversification breadth, organization structure, competitive strategy, and line IT knowledge. For each contingency, Table VI provides a definition and examples for IT governance research references. It presents the contingency values that fit a centralized and a decentralized IT governance approach, and a blended or federal approach where applicable.

After discussing these factors and their relevance for data governance with the practitioners in the workshop, two factors from this first set of contingencies were deleted. The first factor was "line IT knowledge." The practitioners agreed that IT knowledge of business managers was not relevant in the context of DQM. Rather, they recommended changing the factor to "line data quality knowledge." However, such a contingency is useless because the underlying assumption of DQM is that business experts possess knowledge about their data requirements and, hence, about data quality. If surveying this factor, this would result in a high degree for all companies. Hence, the factor "line IT knowledge" was deleted without being substituted. The second factor, "firm size," was discussed, with some controversy. Some practitioners demonstrated its applicability for data governance issues, whereas others could not see any relevance of this factor. As some IT governance publications question the applicability of this factor as well [Brown and Grant 2005], it was deleted.

However, the practitioners found two other factors to add to the set: "degree of process harmonization" and "degree of market regulation." Both aspects are considered to be business drivers for DQM, especially with regard to master data [Russom 2006a]. Two partners (companies A and F) are doing a global process harmonization project. Once the business processes, such as procurement or sales, are globally harmonized, they need a more centralized approach to data governance for effectively managing master data underlying these processes (refer to Vogel and Osl [2007]). The factor "degree of process harmonization" ranges between the values "globally harmonized" and "local processes." Two other partners (companies A and D) are operating in highly regulated markets and found that they need a more centralized approach to data governance for coordinating compliance initiatives (refer to Grundei [2006] and Abrams et al. [2007]). The factor "degree of market regulation" ranges from "highly regulated" to "no regulation." 
4: $20 \quad$ K. Weber et al.

Table VII. Contingency Factors Regarding the Coordination of Decision-Making Authority in IT Governance

\begin{tabular}{|l|l|c|c|c|}
\hline Contingency & \multicolumn{1}{|c|}{ Definition } & References & Cooperative & Hierarchical \\
\hline $\begin{array}{l}\text { Decision-making } \\
\text { style/culture }\end{array}$ & $\begin{array}{l}\text { The informal } \\
\text { rules that } \\
\text { determine how } \\
\text { things get } \\
\text { done in the } \\
\text { organization and } \\
\text { the types of } \\
\text { behavior that are } \\
\text { acceptable }\end{array}$ & Dallas 2004] & Consensus-building & $\begin{array}{l}\text { "Command } \\
\text { and control" } \\
\text { culture }\end{array}$ \\
\end{tabular}

\subsection{Coordination of Decision-Making for DQM}

There is only limited research regarding contingency factors and coordination of decision-making authority. Brown [1999] analyzed the interrelation of centralized and federal IT governance designs with horizontal coordination mechanisms. She found that firms with centralized IT governance use formal and informal mechanisms to build lateral organization capabilities between business units and IT units, while firms with federal IT governance use these mechanisms to coordinate corporate and decentralized IT units. Dallas [2004; 2002] argues that IT governance design must reflect and support the decision-making style and the prevailing culture of the company to maximize its effectiveness (refer to Table VII). According to Dallas, enterprizes relying on consensus-building should adopt a cooperative IT governance design, while enterprizes with a command-and-control culture better fit the hierarchical IT governance design.

In the workshop discussion, the practitioners agreed on this factor and its influence on the coordination of decision-making authority. They did not recommend another factor to be added. However, they discussed the difference between this factor and the factor "organization structure." Company C provides a good example for this difference. Although they have a very centralized organization structure, that is, most decisions are made at the top of the management hierarchy, their informal rules of decision-making are very cooperative, in that many employees agree jointly on day-to-day activities and decisions.

\subsection{Practical Implications}

In order to demonstrate the relevance of the identified contingency factors, this section reflects on insights from one of the three action research projects: First, it concisely describes the company, its current situation, and the implications for the corporate data quality project; and second, it characterizes the company with respect to the contingency factors and explains the influence of these factors on the company's data governance design.

This section contains a qualitative description of the researchers' experiences and is, as such, not an empirical validation of the contingency approach. It rather aims at demonstrating the practical implications of this approach. 
Company $\mathrm{A}$ is one of the leading crop protection and crop science companies in the world. With more than 17,000 employees and revenues of more than 5 bn euros in 2007, it serves a global market. The company is a division of a larger group in the chemical industry. The crop protection market is both highly saturated and highly regulated. A prominent example for the latter is the European Union regulation REACH, dealing with the registration, evaluation, authorization, and restriction of chemical substances. Further business drivers are high research and development costs and a lot of mergers and acquisitions in the market. The company is responding to these business drivers with a global business process harmonization initiative aiming at the increase of operational effectiveness and leveraging of synergy potentials in support functions. This strategy has resulted in the consolidation of three regional business process models into a global one. Simultaneously, the company has consolidated their ERP systems into one instance with a common understanding of corporate data objects such as products, vendors, and customers. However, local distinctions such as country-specific product registration requirements or direct sales channels in less developed countries must be taken into account, especially as the profit and loss responsibility is situated on a regional and national level, respectively.

Table VIII characterizes Company A with respect to the contingency factors and explains their influence on the company's data governance design. For this characterization, three practitioners assessed their company independently of one another (for rating intervals, see Tables VI and VII).

Based on the assessment in Table VIII, Figure 4 arranges Company A's data governance design in a matrix. The two dimensions of the matrix represent the two data governance design parameters "organizational placement of DQM activities" and "coordination of decision-making for DQM." The matrix illustrates that the data governance design of Company $\mathrm{A}$ is characterized as rather centralized and cooperative.

\section{DISCUSSION}

Companies need DQM that is capable of combining business-driven and technical perspectives in order to respond to strategic and operational challenges demanding high-quality corporate data. Data governance specifies the framework for decision rights and accountabilities as part of corporate-wide DQM. Based on insights from a community action research project, this article adds to the scientific knowledge about data governance by elaborating on the accountabilities aspect of data governance. Instead of following the universal approach of prior research, this investigation respects the fact that each company requires a specific data governance configuration which fits a set of contingencies. This research aimed at starting a scientific discussion on data governance by transferring concepts from IT governance and organizational theory to the field of data governance.

The flexible data governance model presented in this article facilitates company-specific design of data governance. The four data quality roles (executive sponsor, chief steward, business data steward, and technical data 


\section{4: $22 \quad$ K. Weber et al.}

Table VIII. Influence of Contingency Factors on the Data Governance Design of Company A

\begin{tabular}{|c|c|c|}
\hline Contingency & Assessment Company A & $\begin{array}{c}\text { Consequence for data } \\
\text { governance design }\end{array}$ \\
\hline Performance strategy & Profit & \multirow{3}{*}{$\begin{array}{l}\text { Trend towards centralization } \rightarrow \\
\text { concentration of competencies and } \\
\text { knowledge in one Master Data } \\
\text { Management (MDM) department } \\
\text { in the corporate headquarters }\end{array}$} \\
\hline Diversification breadth & Related (+) & \\
\hline $\begin{array}{l}\text { Organization } \\
\text { structure }\end{array}$ & Centralized (+) & \\
\hline Competitive strategy & Prospector (-) & $\begin{array}{l}\text { Conflicting interests result in } \\
\text { difficulties to enforce MDM mandates } \\
\text { at regional and national levels } \rightarrow \\
\text { in the data quality board regional } \\
\text { representatives discuss and solve } \\
\text { conflicting issues }\end{array}$ \\
\hline $\begin{array}{l}\text { Degree of process } \\
\text { harmonization }\end{array}$ & Globally harmonized (-) & $\begin{array}{l}\text { Trend towards centralization and } \\
\text { influence on the scope of MDM } \rightarrow \\
\text { harmonized product, customer and } \\
\text { vendor MD are key to globally } \\
\text { harmonized processes (matching of } \\
\text { identification numbers is not } \\
\text { sufficient) }\end{array}$ \\
\hline $\begin{array}{l}\text { Degree of market } \\
\text { regulation }\end{array}$ & Highly regulated (+) & $\begin{array}{l}\text { Expertise regarding country } \\
\text { regulation is provided by local } \\
\text { data stewards }\end{array}$ \\
\hline $\begin{array}{l}\text { Decision-making } \\
\text { style/culture }\end{array}$ & Consensus-building (-) & $\begin{array}{l}\text { Many "C" in the data } \\
\text { governance model point to a } \\
\text { cooperative approach to data } \\
\text { governance }\end{array}$ \\
\hline
\end{tabular}

Key: (-) trend towards the middle of the interval, (+) trend towards the end of the interval.

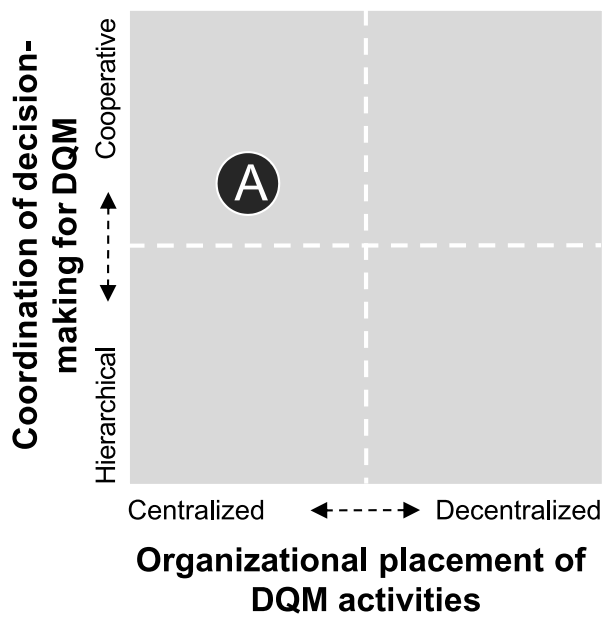

Fig. 4. Company A's data governance design characterized by the two design parameters.

ACM Journal of Data and Information Quality, Vol. 1, No. 1, Article 4, Pub. date: June 2009. 
steward) plus one committee (data quality board), together with the fundamental decision areas and main activities of DQM referring to strategic, organizational, and system-related aspects, build the foundation on which companies can start designing their own data governance solution. With the model, companies can document and structure data quality roles, their type of interaction with the DQM activities, and the decision-making approach. The data governance model can be used as a company-wide communication device for the organization of DQM.

The contingency approach to data governance presented in this article explains the relationship between the design of the data governance model and successful DQM, which is influenced by seven contingency factors: performance strategy, diversification breadth, organization structure, competitive strategy, degree of process harmonization, degree of market regulation, and decision-making style. Although the contingency model has not been tested empirically, its suitability could be demonstrated in a data governance action research project in a chemical company. Companies that understand the correlations in the contingency model can design a data governance configuration that fits their specific requirements, hence maximizing the positive contribution of DQM to their business objectives.

Finally, a number of limitations need to be considered. This article transfers knowledge from IT governance research to data governance. DQM is not fully comparable to IT management, and neither are data governance and IT governance. Nevertheless, IT governance research pursues similar objectives. Moreover, it has a longer and more profound track record. The research on contingencies influencing IT governance models is used as a starting point for the data governance contingency model. Although the researchers made a first qualitative evaluation of the contingency factors, the contingency model should be validated through a quantitative empirical survey in order to demonstrate generalizability of the factors and their influence on data governance design. It is also important to elaborate more precisely on the third factor in this model: how to define and measure DQM success. However, changing organizational aspects of a company is a long process which sometimes takes several years to show visible results [Kotter 1995]. To mitigate the influence of IT governance and for a more elaborate investigation of the allocation of decision rights, organizational studies such as corporate governance, organizational theory, and organizational psychology, as well as quality management research, need to be considered.

This research has raised many questions in need of further investigation. An analysis of the guidelines and policy aspect of data governance is recommended in order to enforce accountability as defined in the data governance model. To acknowledge more complex organizational models for DQM, the applicability of additional design parameters should be analyzed, such as a time dimension which respects the fact that the configuration might evolve over time [Dallas 2002; Rau 2004]. For practical application, the data governance components described in this article (data governance model, design parameters, contingency model) may be arranged in a methodology to allow for a systematic approach for establishing data governance. 


\section{4: $24 \quad$ K. Weber et al.}

\section{APPENDIX}

Table IX. Description of Research Project Industry Partner Companies

\begin{tabular}{|l|l|l|l|l|l|l|}
\hline Company & \multicolumn{1}{|c|}{ A } & \multicolumn{1}{c|}{ B } & \multicolumn{1}{c|}{ C } & \multicolumn{1}{c|}{ D } & \multicolumn{1}{c|}{ F } \\
\hline Industry & Chemicals & $\begin{array}{l}\text { Automotive } \\
\text { OEM }\end{array}$ & $\begin{array}{l}\text { Public } \\
\text { Sector }\end{array}$ & TelCo & $\begin{array}{l}\text { Consumer } \\
\text { Products }\end{array}$ & $\begin{array}{l}\text { Automotive } \\
\text { Supplier }\end{array}$ \\
\hline $\begin{array}{l}\text { Scope of } \\
\text { initiative }\end{array}$ & $\begin{array}{l}\text { corporate- } \\
\text { wide }\end{array}$ & $\begin{array}{l}\text { line of } \\
\text { business }\end{array}$ & $\begin{array}{l}\text { corporate- } \\
\text { wide }\end{array}$ & $\begin{array}{l}\text { lines of } \\
\text { business }\end{array}$ & $\begin{array}{l}\text { corporate- } \\
\text { wide }\end{array}$ & $\begin{array}{l}\text { corporate- } \\
\text { wide }\end{array}$ \\
\hline $\begin{array}{l}\text { Respective } \\
\text { revenue } \\
(2006)\end{array}$ & $5.7 \mathrm{Bn} €$ & $54.6 \mathrm{Bn} €$ & $3.9 \mathrm{Bn} €$ & $61.3 \mathrm{Bn} €$ & $3.4 \mathrm{Bn} €$ & $11.6 \mathrm{Bn} €$ \\
\hline $\begin{array}{l}\text { Number of } \\
\text { Employees } \\
(2006)\end{array}$ & 18,000 & 100,000 & 38,000 & 250,000 & 21,000 & 56,000 \\
\hline $\begin{array}{l}\text { Markets } \\
\text { served }\end{array}$ & Global & global & national \\
\hline $\begin{array}{l}\text { SME } \\
\text { roles }\end{array}$ & $\begin{array}{l}\text { Head of } \\
\text { O\&IT } \\
\text { Technical } \\
\text { Data } \\
\text { Steward }\end{array}$ & $\begin{array}{l}\text { Head of IT } \\
\text { Architecture } \\
\text { and } \\
\text { Planning }\end{array}$ & $\begin{array}{l}\text { Project } \\
\text { IDM, } \\
\text { Head of } \\
\text { Strategic } \\
\text { IDM }\end{array}$ & $\begin{array}{l}\text { Head of } \\
\text { Manager } \\
\text { MDM }\end{array}$ & $\begin{array}{l}\text { Manager } \\
\text { O\&IT, } \\
\text { Project } \\
\text { Manager } \\
\text { MDM }\end{array}$ & $\begin{array}{l}\text { MDational } \\
\text { Project } \\
\text { Manager } \\
\text { MDM }\end{array}$ \\
\hline
\end{tabular}

Key: IDM = Infrastructure Data Management, MDM = Master Data Management, O\&IT = Organization and IT.

\section{REFERENCES}

Abrams, C., Von Känel, J., Müller, S., Pfitzmann, B., and Ruschka-Taylor, S. 2007. Optimized enterprize risk management. IBM Syst. J. 46, 2, 219-234.

Ahituv, N., Neumann, S., And Zviran, M. 1989. Factors affecting the policy for distributing computing resources. MIS Quart. 13, 4, 389-401.

BAskerville, R. AND Myers, M. D. 2004. Special issue on action research in information systems: Making IS research relevant to practice - Foreword. MIS Quart. 28, 3, 329-335.

Baskerville, R. L. AND Wood-Harper, A. T. 1998. Diversity in information systems action research methods. Eur. J. Inf. Syst. 7, 90-107.

BittereR, A. AND Newman, D. 2007. Organizing for data quality. Gartner Research, Stamford, CT.

Boynton, A. C. AND ZMUD, R. W. 1987. Information technology planning in the 1990's: Directions for practice and research. MIS Quart. 11, 1, 58-71.

Brown, A. E. AND Grant, G. G. 2005. Framing the frameworks: A review of IT governance research. Comm. Assoc. Inf. Syst. 15, 696-712.

BRown, C. V. 1997. Examining the emergence of hybrid IS governance solutions: Evidence from a single case site. Inf. Syst. Res. 8, 1, 69-94.

BRown, C. V. 1999. Horizontal mechanisms under differing IS organization contexts. MIS Quart. $23,3,421-454$.

Brown, C. V. AND Magill, S. L. 1998. Reconceptualizing the context-design issue for the information systems function. Organiz. Sci. 9, 2, 176-194.

Burns, T. AND StAlKer, G. 1961. The Management of Innovation. Tavistock, London.

Cohen, S. And Roussel, J. 2004. Strategic Supply Chain Management: The Five Disciplines for Top Performance. McGraw-Hill.

CRiÉ, D. AND Micheaux, A. 2006. From customer data to value: What is lacking in the information chain? Datab. Market. Customer Strategy Manage. 13, 4, 282-299.

Crowe, A. 2005. The Pmp Exam: How to Pass on Your First Try. 3rd Ed., Velociteach Press, Kennesaw, GE.

ACM Journal of Data and Information Quality, Vol. 1, No. 1, Article 4, Pub. date: June 2009. 
Curtis, D., Colville, R. J., Haight, C., AND Brittain, K. 2005. Use and awareness of ITIL is increasing. Gartner Research, Stamford.

DAhlberg, T. AND KIVIJÄRVI, H. 2006. An integrated framework for IT governance and the development and validation of an assessment instrument. In Proceedings of the 39th Annual Hawaii International Conference on System Science. Vol. 8, 194-192. IEEE Computer Society,

DAllas, S. 2002. Six IT governance rules to boost IT and user credibility. Gartner Research, Stamford, CT.

DALlAS, S. 2004. IT governance requires decision-making guidelines. Gartner Research, Stamford, CT.

DAVEnPoRT, T. H. 1993. Process Innovation: Reengineering Work through Information Technology. Harvard Business School Press, Cambridge, MA.

DEMBER, M. 2006. Case study: Gaining efficiencies as a result of implementing a data governance program. http://dbq.dpc.or.kr/conference/2006/pdf/Harmony2_02_Martha\%20Dember.pdf.

Donaldson, L. 2001. The Contingency Theory of Organizations. Sage Publications, Thousand Oaks, CA.

DychÉ, J. AND Levy, E. 2006. Customer Data Integration. John Wiley \& Sons, New York.

EIN-DoR, P. AND SEGEV, E. 1982. Organizational context and MIS structure: Some emprirical evidence. MIS Quart. 6, 3, 55-68.

English, L. P. 1999. Improving Data Warehouse and Business Information Quality. John Wiley \& Sons, New York.

EPPLER, M. J. 2006. Managing Information Quality. 2nd ed. Springer, Berlin, Germany.

FRIEDMAN, T. 2006. Gartner study on data quality shows that IT still bears the burden, G00137680. Gartner Group, Stamford, CT.

GRUNDEI, J. 2006. Examining the relationship between trust and control in organizational design. In Organization Design, R. M. Burton, et al., Eds. Springer Science + Business Media LLC, Boston, MA, 43-65.

Hammer, M. AND Champy, J. 1993. Reengineering the Corporation: A Manifesto for Business Revolution. Nicholas Brealey Publishing, London.

HodgKinson, S. L. 1996. The role of the corporate IT function in the federal IT organization. In Information Management: The Organizational Dimension, M. J. Earl, Ed. Oxford University Press, Oxford, UK.

HuAnG, K.-T., LeE, Y. W., AND WAnG, R. Y. 1999. Quality Information and Knowledge. Prentice Hall, NJ.

Hult, M. AND LENNUnG, S.-A. 1980. Towards a definition of action research: A note and a bibliography. J. Manag. Studies 17, 2, 241-250.

IT GovernanCE Institute. 2005. CobiT 4.0: Control objectives, management guidelines, maturity models. IT Governance Institute, Rolling Meadows, IL.

JARVINEN, P. H. 2000. Research questions guiding selection of an appropriate research method. In Proceedings of the 8th European Conference on Information Systems, 124-131.

Kagermann, H. And Österle, H. 2006. Geschäftsmodelle 2010 - Wie CEOs Unternehmen transformieren. Frankfurter Allgemeine Buch, Frankfurt, Germany.

KEATS, B. AND O'NEILL, H. M. 2001. Organizational structure: Looking through a strategy lens. In The Blackwell Handbook of Strategic Management, Blackwell Publishing, 520-542.

KorAC-KAKABADSE, N. AND KAKABADSE, A. 2001. IS/IT Governance: Need for an Integrated Model. Corp. Govern. 1, 4, 9-11.

Kotter, J. P. 1995. Leading change: Why transformation efforts fail. Harvard Bus. Rev. Mar.Apr., 59-67.

LAWRENCE, P. R. AND LoRsCH, J. W. 1967. Organization and Environment. Harvard University Press, Cambridge, MA.

Madnick, S., Wang, R., Chettayar, K., Dravis, F., Funk, J., Katz-HaAs, R., Lee, C., LEE, Y., XIAN, X., AND BHANSALI, S. 2004. Exemplifying Business Opportunities for Improving Data Quality through Corporate Household Research. MIT Sloan School of Management, Cambridge, MA. 


\section{4: $26 \quad$ K. Weber et al.}

Marco, D. AND SMith, A. M. 2006. Metadata management \& enterprize architecture: Understanding data governance and stewardship. DM Rev. Sept.-Oct.-Nov.

Miller, D. 1992. Environmental fit versus internal fit. Organiz. Sci. 3, 2, 159-178.

Newman, D. AND Logan, D. 2006a. Achieving agility: How enterprize information management overcomes information silos, Gartner Research, Stamford, CT.

NEwman, D. AND Logan, D. 2006b. Governance is an essential building block for enterprize information management. Gartner Research, Stamford, CT.

NoHR, H. 2001. Management der Informationsqualität, Nr. 3/2001, Fachhochschule Stuttgart, Stuttgart.

OECD 2004. OECD Principles of Corporate Governance. OECD Publications Service, Paris, France.

Olson, M. H. AND CheRVANY, N. L. 1980. The relationship between organizational characteristics and the structure of the information services function. MIS Quart. 4, 2, 57-68.

Österle, H. AND Winter, R. 2003. Business engineering. In Business Engineering, H. Österle and R. Winter Eds. Springer, Berlin, Germany, 3-18.

PATEL, N. V. 2002. Emergent forms of IT governance to support global e-business models. J. Inf. Tech. Theory Appl. 4, 2, 33-48.

Peterson, R. 2004. Crafting information technology governance. Inf. Syst. Manag. 21, 4, 7-22.

PRICE, R. AND Shanks, G. 2005. A semiotic information quality framework: Development and comparative analysis. J. Inf. Tech. 20, 88-102.

RAU, K. G. 2004. Effective governance of IT: Design objectives, roles, and relationships. Inf. Syst. Manag. 21, 4, 35-42.

Redman, T. C. 1996. Data Quality for the Information Age. Artech House, London, UK.

Redman, T. C. 2000. Data Quality. Digital Press, Boston, MA.

Reid, A. AND CATterall, M. 2005. Invisible data quality issues in a CRM implementation. J. Datab. Mark. Customer Strategy Manag. 12, 4, 305-314.

Russom, P. 2006a. Master data management: Consensus-driven data definitions for crossapplication consistency. The Data Warehousing Institute, Seattle, WA.

RUssom, P. 2006b. Taking data quality to the enterprize through data governance. The Data Warehousing Institute, Seattle, WA.

SAmbamurThy, V. AND ZMUd, R. W. 1999. Arrangements for information technology governance: A theory of multiple contingencies. MIS Quart. 23, 2, 261-290.

Senge, P. M. AND Scharmer, O. 2001. Community action research. In Handbook of Action Research, P. Reason and H. Bradbury Eds. Sage Publications, Thousand Oaks, CA, 238-249.

Shankaranarayan, G., ZiAD, M., AND WANG, R. Y. 2003. Managing data quality in dynamic decision environments: An information product approach. J. Datab. Manag. 14, 4, 14-32.

Susman, G. I. AND Evered, R. D. 1978. An assessment of the scientific merits of action research. Admin. Sci. Quart. 23, 4, 582-603.

SWANTON, B. 2005. Master data management organizations: A balance of control and responsibility. AMR Research, Boston, MA.

TAVAKOLIAN, H. 1989. Linking the information technology structure with organizational competitive strategy: A survey. MIS Quart. 13, 3, 308-318.

Tellkamp, C., Angerer, A., Fleisch, E., And Corsten, D. 2004. From pallet to shelf: Improving data quality in retail supply chains using RFID. Cutter IT J. 17, 9, 19-24.

Umanath, N. S. 2003. The concept of contingency beyond "It depends": Illustration from IS research stream. Inf. Manag. 40, 551-562.

VermeER, B. H. P. J. 2000. How important is data quality for evaluating the impact of EDI on global supply chains? In Stärkung der Integrationsfähigkeit durch Prozessharmonisierung und Stammdatenmanagement auf Basis einer globalen, T. Vogel and P. Osl Eds. ERP-Lösung, Beitrag.

WANG, R. Y. 1998. A product perspective on total data quality management. Comm. ACM 41, 2, 58-65.

ACM Journal of Data and Information Quality, Vol. 1, No. 1, Article 4, Pub. date: June 2009. 
WANG, R. Y., LEE, Y., PiPINo, L., AND StRong, D. 1998a. Manage your information as a product. Sloan Manag. Rev. 39, 4, 95-105.

WANG, R. Y., Lee, Y. W., PiPIno, L. L., AND Strong, D. M. 1998b. Manage your information as a product. Sloan Manag. Rev. 39, 4, 95-105.

WANG, R. Y. AND Strong, D. 1996. Beyond accuracy: What data quality means to data consumers. J. Manag. Inf. Syst. 12, 4, 5-34.

WEILL, P. 2004. Don't just lead, govern: How top-performing firms govern IT. MIS Quart. Exec. 3, $1,1-17$.

WeILl, P. AND Ross, J. 2005. A matrixed approach to designing IT governance. MIT Sloan Manag. Rev. 46, 2, 25-34.

WENDE, K. 2007. A model for data governance - Organizing accountabilities for data quality management. http://www.acis2007.usq.edu.au/assets/slides/Kristin_Wende_DataGovernance_V2.pdf.

Woodward, J. 1980. Industrial Organization: Theory and Practice. 2nd, Ed. Oxford University Press, Oxford, UK.

ZAHAY, D. AND GRIFFIN, A. 2003. Information antecedents of personalisation and customisation in business-to-business service markets. J. Database Mark. 10, 3, 255-271.

Received December 2007; revised February 2009; accepted February 2009 